\title{
A REVIEW OF THE SURGERY OF THE THORACIC DUCT \\ BY
}

\author{
J. KEITH ROSS \\ From the Brompton Hospital, London
}

"It will be found, however . . . that nature, with a kind regard to our preservation, has provided security against this evil, so that a considerable degree of disease may exist in the principal trunk of the absorbents without any permanent interruption to the progress of absorption."

Astley Cooper, 1798.

If a moment in time can ever be said to mark the beginning of interest in a subject, in this instance it must have been in 1622 when Gasparo Aselli pricked a lacteal in a dog's mesentery and saw the chyle come out.

Possibly because it is seldom seen, and because it manifests its importance only when damaged and leaking, the thoracic duct has an aura of mystery. The problem of a chylous effusion in the pleural cavity is not a common one, but it tends to occur when least expected, and a definite plan of action, of necessity often based on the experience of others, must be available to meet the situation when it arises. Further, with the increasing incidence both of chest injury associated with modern travel, and of surgical procedures involving the thoracic contents and vertebral column, chylothorax may well be met more often.

\section{SuRgical ANATOMY}

Developmentally the thoracic duct has all the potential of an inconstant anatomical structure (Kausel, Reeve, Stein, Alley, and Stranahan, 1957; Randolph and Gross, 1957), and this is borne out by the variations found when it is studied in the adult (Davis, 1915; Van Pernis, 1949 ; Meade, Head, and Moen, 1950 ; Stranahan, Alley, Kausel, and Reeve, 1956).

The "normal" course, as described in textbooks of anatomy (Gray, 1958), is followed by the duct in only a little over a half of individuals, and two or more main ducts are present at some stage in its course in 40 to $60 \%$ of people (Van Pernis, 1949 ; Kausel et al., 1957).

In addition to the chief ending of the duct at or near the left jugulo-subclavian junction, other minor lymphatico-venous anastomoses exist between the thoracic duct system and the azygos, intercostal, and lumbar veins. The richness of this collateral circulation is such that the main thoracic duct can be ligated safely at any point in its thoracic or cervical course without harmful effect.

The classically described course of the thoracic duct explains why damage to it below the level of the fifth or sixth thoracic vertebra usually results in a right-sided chylous effusion, and damage above this level to an effusion on the left.

Low in its intrathoracic course the duct is most easily found where it lies on the vertebral column between the aorta and the azygos vein; here the greater splanchnic nerve is a close relation on the right side. This is the most favourable site for elective ligation of the thoracic duct in the chest, as well as a place where it is frequently damaged, and its situation means that it is most easily reached from the right side. If a left-sided approach has to be used, the aorta must be mobilized to get at the duct, which may be reached either in front of or behind the aorta.

Any operation in or about the mediastinum carries with it the risk of damage to the main thoracic duct or a major tributary, but the duct is particularly vulnerable in the upper part of the chest in any procedure involving mobilization of the aortic arch, left subclavian artery, or oesophagus. Here the duct lies along the left border of the oesophagus, is crossed by the aortic arch, and comes to lie behind the beginning of the left subclavian artery close to the mediastinal pleura.

Multiplicity of the duct is clearly important when the main chyle pathway has to be interrupted to control a chylous fistula, if the actual point of leakage cannot be found and satisfactorily dealt with. Although opinions differ (Stranahan et al., 1956), a double or plexiform duct system may be found from the level of the cisterna chyli upwards, and such an arrangement could, theoretically, be difficult to manage. In practice, the remarkable success of mediastinal thoracic duct ligation may indicate that this is a theoretical rather than a practical pitfall, even though the 
incidence of multiple duct patterns at diaphragmatic level has been put as high as $30 \%$.

The Right Lymphatic Duct.-This receives lymph from the right side of the head and neck, the right arm, the right side of the chest, and both lungs. It opens into the right jugulo-subclavian angle either as a single channel or its tributaries may end independently. Cross-communications of its broncho-mediastinal trunk with thoracic duct tributaries are important collateral channels.

\section{Physiology of the Thoracic Duct}

FLow.-The thoracic duct is a muscular endothelial-lined tube containing multiple valves. The forward, or upward, flow of chyle within the duct is maintained by the following factors (Acevedo, 1943 ; Birt and Connolly, 1952; Randolph and Gross, 1957) :

Vis a Tergo.-The inflow of chyle into the lacteal system provides a "vis a tergo" which in turn is governed by the intake of food and liquid into the intestine, and is augmented by intestinal movement.

Forward flow may be helped by intermittent compression of the cisterna chyli between the right crus of the diaphragm and the aorta during breathing, and by increased intra-abdominal pressure on inspiration.

Negative Intrathoracic Pressure.-The negative intrathoracic pressure on inspiration, and the resulting pressure gradient between the abdomen and the chest, is said to help the upward flow of chyle.

Contraction of the Thoracic Duct Wall.-This is probably the most important factor.

Spontaneous rhythmic contractions of the thoracic duct wall have been seen (Kinmonth and Taylor, 1956), and the duct has been watched emptying itself at regular intervals of some 10 to 15 seconds into the subclavian vein. Gushes of chyle every 13 to 14 seconds were timed following a puncture wound of the duct by the same observers, who also recorded rhythmic contractions in large retroperitoneal lymphatics, independent of respiratory movements. The cisterna chyli itself is a muscular structure, and its movements must also help to propel chyle along the duct.

There is evidence that the autonomic nervous system plays a part in the control of the duct musculature. In 1882, Quénu and Darier described a nervous plexus of fine non-myelinated fibres in the wall of the thoracic duct of the dog (Acevedo,
1943). Acevedo showed that stimulation of the distal cut end of the vagus causes constriction of the thoracic duct, and that acetylcholine given intravenously or directly into the duct causes contraction of the duct muscle with reduction of flow. Adrenaline causes dilatation of the duct, and this behaviour is an interesting contrast to that of blood vessels when acted upon by adrenaline and acetylcholine.

Blood Flow in the Great Veins.-A venturi, or suction, effect may be produced by the rapid flow of blood in the great veins past the mouth of the duct at its termination.

\section{Volume and Rate of Flow of Chyle}

Both the volume and rate of flow of chyle vary enormously with meals and are particularly affected by the fat content of food, being increased when the fat content is high.

Volumes of up to $2,500 \mathrm{ml}$. of chyle in 24 hours have been collected from the cannulated human thoracic duct (Watne, Hatiboglu, and Moore, 1960), and the flow rate has been shown to vary between 14 and $110 \mathrm{ml}$. per hour (Shafiroff and Kan, 1959). Aspiration of the chest may result in the loss of between 2 and 3 litres of chyle daily in the presence of a chylous fistula (Dillard and Perkins, 1958).

Water taken by mouth can increase the flow of chyle by $20 \%$, and an ordinary hospital meal can cause a threefold increase in flow (Crandall and Barker, 1943). Starvation reduces flow to the merest trickle of clear lymph.

Skeletal muscle activity has a tendency to increase thoracic duct flow, but this is neither constant nor very great.

Morphia has been found to reduce the flow of chyle to less than half the resting rate (Crandall and Barker, 1943), but this observation has not been confirmed (Dumont and Mulholland, 1960). Other observers have found that neither morphia nor atropine had any effect on thoracic duct flow (Watne et al., 1960).

The thoracic duct pressure at the height of maximum flow is $10-28 \mathrm{~cm}$. of water (Shafiroff and Kan, 1959).

\section{The Thoracic Duct and Fat Metabolism}

Thoracic duct lymph contains 0.4-6.0 g. \% fat, and $60 \%-70 \%$ of ingested fat is conveyed to the blood stream by way of the thoracic duct. This is made up of neutral fat, free fatty acids, phospholipid, sphingomyelin, cholesterol, and cholesterol 
esters. Neutral fat is found in the form of minute globules, or chylomicrons, $0.5 \mu$ or less in diameter.

The precise way in which fat is absorbed from the intestine still remains in doubt, but it must be accepted that human chyle contains free fatty acid. The "partition" hypothesis (Frazer, 1943; Auld and Needham, 1951), suggesting that fatty acids travel exclusively to the liver in the portal blood and neutral fat by way of the lymphatics to the systemic circulation and thence to fat depots, does not explain why fatty acids are so consistently found in human chyle. This paradox is mentioned by Auld, whose observations on the fate of stained neutral fat and fatty acid in a man with chylothorax tended to support the partition theory. Fat absorption studies in a child with chylothorax have shown that unsaturated fatty acids have a high coefficient of lymphatic absorption, a finding directly opposing Frazer's theory (Fernandes, van de Kamer, and Weijers, 1955). This is a matter of practical importance, because the bacteriostatic properties of chyle are believed to be related to its high fatty acid content.

The rate of passage of ingested fat from the intestine to the cervical end of the thoracic duct was determined by Crandall (Crandall and Barker, 1943) ; $250 \mathrm{mg}$. of Sudan IV in $50 \mathrm{ml}$. of olive oil given by mouth had an appearance time of 1 hour and 27 minutes at the fistula in the neck.

If neutral fat in the form of olive oil is labelled with radioactive iodine $\left(\mathrm{I}^{131}\right)$ and given by mouth, peak radioactivity in the venous blood occurs within six hours in normal individuals (Likoff, Berkowitz, Woldow, Jacobs, and Sklaroff, 1958). In the absence of faulty absorption, such a test could be used to give an index of the speed and. efficiency of neutral fat transfer through the chyle system.

\section{The Thoracic Duct and Protein Metabolism}

It seems likely that any protein which passes unchanged through the intestinal mucosa enters the lymphatics and not the blood capillaries (Yoffey and Courtice, 1956). The capacity to absorb quantities of unchanged protein of large molecular size (colostrum protein) disappears within the first few days of life, but protein of smaller molecular size (egg albumen) has been recovered from thoracic duct lymph after being fed by stomach tube in dogs (Alexander, Shirley, and Allen, 1936).

Thoracic duct lymph contains about 4\% protein (Wright, 1945) consisting of albumin, globulin, fibrinogen, and prothrombin, and with an albumin : globulin ratio of $3: 1$.

There is experimental evidence to suggest that the thoracic duct is the main pathway for the return of extravascular plasma protein and for the transfer of depot protein, chiefly from the liver, in times of stress (CoTui, Barcham, and Shafiroff, 1944). If experimental animals are bled $25 \%$ of their blood volume, the plasma protein level is restored to normal within 48 hours. If the experiment is repeated in animals whose thoracic ducts have been ligated in the neck immediately beforehand, a sustained fall in plasma protein occurs which takes eight days to return to normal levels.

\section{The Thoracic Duct and Cellular Elements OF THE BLOOD}

The average daily output of lymphocytes from the thoracic duct in man has been estimated at 35,546 millions (Yoffey and Courtice, 1956). These calculations exclude the lymph of the right lymph duct, which is known to be capable of high lymphocyte content.

The lymphocyte count of human chyle varies between 400 and 6,800 per c.mm. (Shafiroff and Kan, 1959), and for practical purposes all mononuclear cells found in chyle are lymphocytes.

Erythrocytes are always found in thoracic duct lymph, the count varying between 50 and 600 per c.mm. (Shafiroff and Kan, 1959), but monocytes are normally not found and only scanty eosinophils.

Under abnormal conditions macrophages may be seen, but plasma cells are rare: large, blastlike cells, of which the nature and fate are unknown, may be found, sometimes in mitosis (Yoffey and Courtice, 1956).

\section{The Thoracic Duct and the Pancreas}

In 1902 Bainbridge demonstrated increased thoracic duct flow after giving secretin, and Blalock, Robinson, Cunningham, and Gray produced massive lymphoedema of the pancreas in the course of their lymphatic obstruction experiments in 1937. By cannulating the thoracic duct in human subjects, it has been shown that it transmits pancreatic enzymes in quantity, that their amount is increased by the giving of secretin and still further increased after giving morphia to cause constriction of the sphincter mechanism at the duodenal end of the pancreatic duct (Dumont and Mulholland, 1960). Good evidence is produced that the thoracic duct is an important direct pathway for external pancreatic 
secretion, involving lipase, amylase, and desoxyribonuclease. Dumont and Mulholland suggest that pancreatic enzymes in the thoracic duct system may somehow help fat transfer, or in some way prepare fat before its release into the systemic venous blood. It is conceivable that pancreatic lipase, in the alkaline medium of chyle, might continue the breakdown of neutral fat in transit despite the absence of bile salts. The idea is also put forward by Dumont and Mulholland that the thoracic duct may prove to be important in the circulation of insulin.

\section{Physiological Effects of Thoracic Duct FISTULA}

First, such a fistula results in the loss of water and electrolytes, the electrolyte content of chyle being, for practical purposes, that of the blood plasma ; the volumes that can be lost have already been mentioned.

The loss of fat and fat-soluble vitamins, which can be considerable and results in a serious metabolic deficit, is better tolerated than the protein loss, which leads to a steadily falling plasma protein level, wasting, and famine oedema.

The severity of this problem is well illustrated by Little, Harrison, and Blalock in 1942, from whose patient a total of 500 litres of chyle was removed during a period of 18 months. During six months of this time 1581 . of chyle was removed containing $3 \%$ protein, a total protein loss of $4,750 \mathrm{~g}$., or $25 \mathrm{~g}$. per day. Other authors stress the difficulty, " amounting to hopelessness," of maintaining adequate plasma protein levels by dietary means in the presence of persistent chyle loss (Baldridge and Lewis, 1948).

Circulating lymphocytes are greatly reduced in number, and antibodies are probably also lost. For some unknown reason the eosinophil count also falls.
The total effect of a persistent thoracic duct fistula is disastrous, and death is inevitable once supportive treatment fails unless the fistula closes spontaneously or is surgically closed.

\section{Physiological Effects of Thoracic Duct Ligation}

It has been shown repeatedly, both experimentally and clinically, that ligation of the thoracic duct is not lethal as was once believed, and that it is not followed by the extravasation of chyle distal to the point of ligature. This is true regardless of the level of ligation, and is due to the lymphatic collateral circulation (Lee, 1922). Extirpation of the thoracic duct (Maurer, 1956) and removal of the cisterna chyli (McGregor, 1953) in man have not been followed by harmful effects.

Experimentally, it is difficult to exclude lymph from the blood stream to such an extent that chylous effusions occur in the serous cavities (Blalock et al., 1937; Robinson, Cunningham, Blalock, Gray, and Rogers, 1937).

The intraduct pressure can rise to surprising heights after ligation. Lampson (1948) noted a pressure of $35 \mathrm{~cm}$. of water, and pressures as high as $50 \mathrm{~mm}$. $\mathrm{Hg}$ have been recorded after obstruction of the human thoracic duct (Kinmonth and Sharpey-Schafer, 1960) (Fig. 1): the pressure falls with the opening up of collateral vessels.

Ligation of the thoracic duct is followed by no outward signs of nutritional disturbance, but the blood fat level, which is normally $500-700 \mathrm{mg}$. \% total fat, has been shown to fall to $280 \mathrm{mg}$. \% within three hours of the duct being tied. In a control series the mean post-operative total blood fat was $615 \mathrm{mg}$.\%. Normal levels were reached by the sixteenth day following thoracic duct ligation (Ehrenhaft and Meyers, 1948).

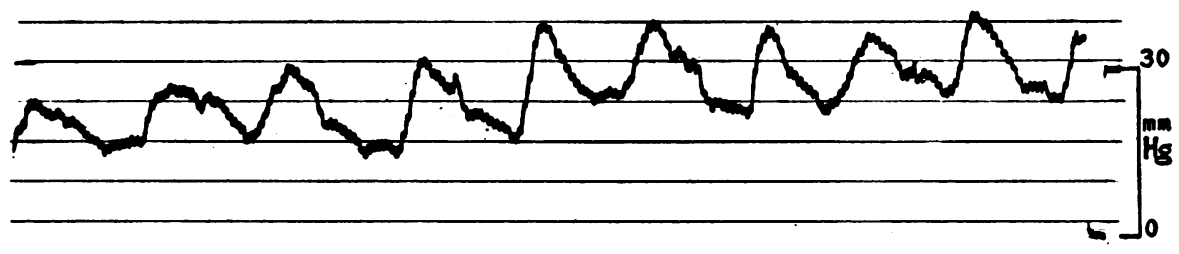

Fig. 1.-Human thoracic duct pressure tracing $(t=1 \mathrm{sec}$.), in which the frequency of the rhythmic pressure waves can be seen, and the build-up in pressure after obstruction. Here the pressure rose about $20 \mathrm{~mm}$. $\mathbf{H g}$; over a greater time the rise was as much as $\mathbf{5 0} \mathbf{~ m m}$. Hg. (Published by permission of Professor J. B. Kinmonth.) 
The lymphocyte count in the peripheral blood falls dramatically within a few hours of the thoracic duct being tied to a value $50-60 \%$ of normal, becoming normal again within seven to eleven days.

\section{Pathology of Thoracic Duct and Aetiology OF CHYLOTHORAX}

Congenital.-Single or multiple thoracic duct fistulae can be found soon after birth. The occurrence of chylothorax early in infancy, in the absence of notable birth trauma, suggests one of two things. Either a congenital weakness of the duct can exist so that it is unable to withstand the usual stress of childbirth, or there could be a frank congenital fistula which becomes apparent once the infant is being fed. The failure of junction of multiple segmental components of the embryonic duct is a possible explanation, upheld by the occasional finding of multiple fistulae at operation for chylothorax early in infancy (Randolph and Gross, 1957).

Traumatic.-There are two ways in which the thoracic duct may be damaged by closed injury - penetrating injury or at operation.

Penetrating Injury.-The commonest form of non-penetrating injury to the thoracic duct is that due to sudden hyperextension of the spine with rupture of the duct just above the diaphragm. Sudden stretching over the vertebral bodies may alone be enough to tear the duct, but some believe that duct fixation as the result of prior injury or disease is responsible for making it susceptible to such violence (Meade et al., 1950 ; Meade, 1952). The less the severity of the closed trauma the more likely it is that some other factor is involved.

It is possible that the right crus of the diaphragm may damage the thoracic duct by shearing (Birt and Connolly, 1952), and if the duct is full after a fatty meal it is considered more liable to injury.

Blast and crush injuries of the chest, vomiting, or a violent bout of coughing may be associated with tearing of the thoracic duct.

There are two remarkable facts about such a chylous fistula. One is that there is nearly always a latent interval, usually of from two to 10 days, but sometimes of weeks or months, between the time of injury and the onset of the chylous pleural effusion; and the other is the reluctance of such fistulae to close spontaneously.

The latent interval is due to the fact that, following rupture of the duct, chyle accumulates in the posterior mediastinum-the so-called "chyloma" - and finally ruptures the mediastinal pleura, usually on the right side at the base of the pulmonary ligament.

Thoracic duct fistulae do not all obey the law that fistulae tend to close in the absence of distal obstruction. Spontaneous sealing of thoracic duct fistulae after closed injury may be expected in only $50 \%$ of such cases, and death may be expected in the remaining $50 \%$ unless the fistula is surgically closed.

Gunshot and stab wounds of the thoracic duct are unusual and apt to be overshadowed by damage to other structures of more immediate importance in the vicinity. Such wounds do, however, occur (Crandall and Barker, 1943; Schnug and Ransohoff, 1943; Loe, 1946; Goorwitch, 1955).

Injury at Operation.-The cervical part of the thoracic duct may be injured during such operations as block dissection of the neck and scalene node biopsy: the resultant fistula frequently closes spontaneously, but persistent chyle leaks are readily controlled by duct ligation in the wound.

Chylothorax has been reported following almost every known thoracic operation, and the list of isolated case reports is a formidable one. However, splanchnicectomy (Hodge and Bridges, 1948 ; Crafoord, 1941), resection of coarctation of the aorta, and Blalock's operation (Shumacker and Moore, 1951 ; Baffes and Potts, 1954) are among those most frequently complicated by chylothorax. Chyle may be aspirated after pneumonectomy or from the Semb space after thoracoplasty and be mistaken for pus, which is a common error whenever chyle first appears in the syringe. Chylothorax due to injury of a thoracic duct tributary has followed translumbar aortography (Gaspar and Secrest, 1957), and, keeping pace with recent advances in surgery, has followed the closure of a ventricular septal defect with the use of cardiopulmonary by-pass (Garamella, 1958). The problem of injury to the cervical part of the duct with associated chylothorax is well described by Goorwitch (1955).

Circulatory.-Thrombosis of the great veins into which the thoracic duct drains has been held responsible for chylous effusions (Little et al., 1942), and aneurysms of the thoracic aorta may erode the duct with subsequent fistula formation. Thrombosis of the great veins may be secondary to malignant involvement of the duct and vessel walls, and in this, as well as other malignant chylous leaks, the pericardial sac may be filled with chyle (Yater, 1935). 
INFLAMMATORY.--As the thoracic duct carries lymph from the intestine and peritoneum it is responsible for passing on micro-organisms absorbed from the gut and peritoneal cavity, and may itself become secondarily inflamed in the process. Hence it plays a passive part in such diseases as typhoid, poliomyelitis, and peritonitis, as well as in acute chest infections.

The duct wall can be directly involved by intrathoracic tuberculosis and the lumen may become obstructed in filariasis: both can be associated with chylous fistulae.

Neoplastic.-The pathology of the thoracic duct in relation to benign and malignant processes will be considered.

Benign Intrinsic Cysts and Tumours.-Although cysts of the receptaculum chyli are said to be not uncommon, thoracic duct cysts within the chest are rare, particularly in young people (Emerson, 1950). There are two varieties of thoracic duct cyst: the degenerative and the lymphangiomatous.

Cysts of the degenerative variety are nearly always found in the elderly, being incidentally discovered at necropsy. Degenerative changes occur in the duct wall which have been likened to the changes seen in ageing peripheral veins (Kausel et al., 1957). Calcification in the wall and sometimes atherosclerotic plaque formation have been recorded, and the cysts may be multiple.

Benign lymphangiomata arising in the thoracic duct may also produce single or multiple cyst-like spaces filled with chyle, a more extensive variant being the mediastinal hygroma (Touroff and Seley, 1953) with multiple chyle-containing channels forming a tumour-like mass in the mediastinum. Such cysts are more likely to rupture into the pleura than the degenerative ones, being a rare cause of "spontaneous" chylothorax (Maurer, 1956). They are found as a rule in younger people.

Thoracic Duct and Malignant Disease. Primary malignant tumours of the thoracic duct have never been found.

The duct may become secondarily involved by the lymphatic spread of primary abdominal and intrathoracic cancer, although the precise way in which tumour gains access to the duct lumen is disputed (Willis, 1952; Kausel et al., 1957). Whether the invasion of the lumen is by direct lymphatic permeation in continuity from the primary growth, or by direct invasion of the duct wall from without, or by way of small lymphatics found in the areolar tissue about the duct, it is certain that, once tumour is inside, spread can either be by further permeation (Bland-Sutton, 1917) or by embolism, or by a combination of the two.

The frequency with which the thoracic duct is involved in malignant disease has been variously assessed as $3.6 \%$ (Willis, 1952) and $30 \%$ (Kausel et al., 1957), with other observers arriving at intermediate figures.

By collecting thoracic duct lymph in the living and at necropsy, it has been shown that malignant cells can be found in between $16 \%$ and $23 \%$ of individuals with advanced malignant disease (Watne et al., 1960). Until more is learned about the fate of isolated malignant cells, these observations have to be interpreted in much the same light as the finding of malignant cells in the peripheral blood.

Apart from recognizing the fact that the thoracic duct plays a part in tumour spread, the importance of duct involvement in the present context is that a proportion of those involved in a malignant process will eventually leak chyle. The mechanism of the leak may be the rupture of distended tributary lymphatics by back-pressure (Willis, 1952) or by actual erosion of the duct wall itself (Kausel et al., 1957). The resulting chylous effusion may be unilateral or bilateral, and may be the way that an unsuspected retroserous tumour, such as a lymphosarcoma, presents itself. Chylous ascites followed by chylothorax is a very sinister happening, and strongly suggests the progression of a primary retroperitoneal tumour.

Primary malignant tumours of the pleura may be associated with chylous effusions arising from multiple fistulae, so that the lung appears to weep chyle, and may be complicated by pneumothorax (Dillard and Perkins, 1958).

Spontaneous Chylothorax.-This is a misleading term and has been loosely applied to chylothorax after childbirth, after closed injury, and to those cases secondary to malignant disease. There remain some examples for which no underlying cause can be found (Greenberger and Hurwitz, 1957), but these are uncommon.

Precise classification may be difficult initially, e.g., chylothorax following trivial closed injury may eventually prove to be due to underlying malignant disease.

\section{Complications of Chylothorax}

In addition to the changes already described that follow a thoracic duct fistula, and apart from complications related to the pathology of the 
underlying cause, there are few complications peculiar to chylothorax. Empyema is rare because chyle is bacteriostatic. "Trapping" of the lung by a fibrinous rind happens in a proportion of cases: why this occurs in some and not in others is not clear. Spontaneous pneumothorax and chylothorax may occur together (Calenda and Harris, 1952 ; Greenberger and Hurwitz, 1957), and chyle may be coughed up.

\section{Diagnosis of Chylothorax}

This depends upon the recognition of chyle once it has been aspirated from the chest. The characteristics and composition of chyle are set out in Table I. In traumatic chylothorax, the chyle is frequently blood-stained at first, and this may be misleading.

TABLE I

CHARACTERISTICS AND COMPOSITION OF CHYLE

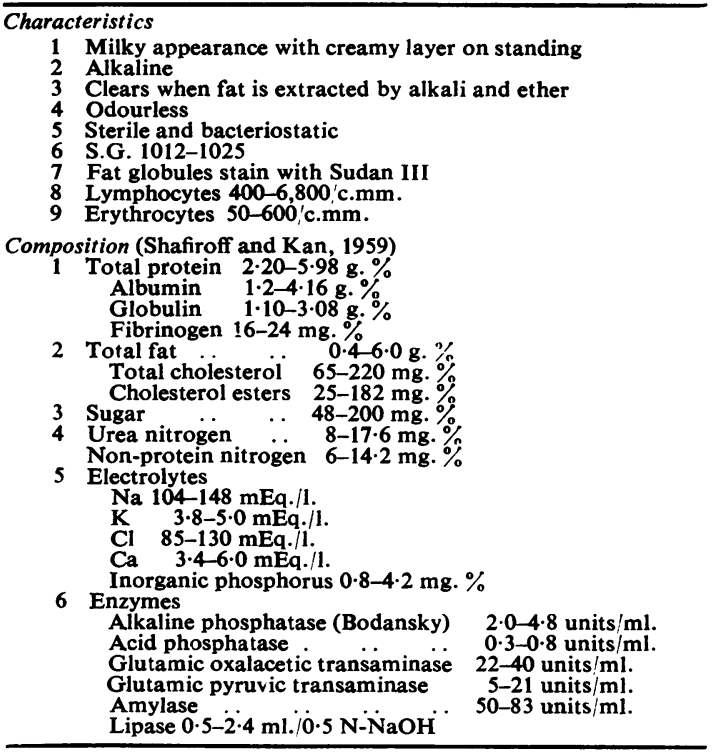

Clinically, the history may be valuable, particularly in the case of chylothorax following closed injury, when the latent interval and sudden onset of a shock-like state and breathlessness, with the appearance of a large effusion, are characteristic. Dramatic relief follows aspiration of the chyle.

Low-grade fever is very often found in all varieties of chylothorax.

Radiologically, the opacity of a chylous effusion is not characteristic, although it may appear less dense relative to other pleural effusions because of its high fat content. Chyle is sufficiently radioopaque to cast a shadow when it occurs as a mediastinal collection (Thorne, 1958) or in a 응 lymphangiomatous cyst (Emerson, 1950).

The diagnostic triad of a rapidly accumulating $\frac{\rho}{\vec{D}}$ pleural effusion, low serum protein level, and a $\propto$ falling lymphocyte count may be of use (Lowman, Hoogerhyde, Waters, and Grant, 1951).

If confirmation is needed that the aspirated fluid is chyle and not "pseudochyle," the patient may $\vec{\omega}$ be given fat to eat stained with a lipophilic dye, $\stackrel{\circ}{P}$ or stained olive oil may be given by Ryle's tube. $\vec{x}$ Sudan III or Sudan IV may be used, but these $\vec{\omega}$ stain the chyle red which may be (macroscopically) mistaken for blood, and greater contrast may be $\vec{N}$ given by using a coal-tar dye such as $\mathrm{D}$ and $\mathrm{C}$ 응 (Drug and Cosmetic) green No. 6 (Klepser and Berry, 1954). One gram of the dye mixed with a 3 quarter of a pound of butter is recommended, spread on bread, and, because of its nasty $\stackrel{5}{工}$ appearance, preferably eaten in the dark.

\section{Treatment of ChylothoraX}

It is not intended to give a historical review of the wide variety of methods used to treat this condition or of the evolution of treatment as advocated to-day ; this has already been admirably $\mathbb{Q}$ done by several authors (Meade, 1952; Goor- $\vec{\Rightarrow}$ witch, 1955 ; Thorne, 1958). It is sufficient to say that the turning point was in 1948 when Lampson first successfully tied the thoracic duct in the chest for the control of a chylous fistula. In what may be called the pre-Lampson era (1695-음 1948) the overall mortality for traumatic chylothorax was $50 \%$ (Shackelford and Fisher, 1938). Since 1948 the overall mortality has dropped to 3 . $10 \%$, and in those treated by duct ligation the mortality is nil (Goorwitch, 1955).

Although there is some evidence that traumatic 응 lymph fistulae in general tend to close spontaneously (Judd and Nix, 1949), the fact remainso that spontaneous closure of a traumatic thoracic duct fistula is quite unpredictable.

The crucial decision in the management of such $N$ cases is how long to carry on with a trial of $\mathrm{w}_{\mathrm{W}}$ conservative treatment. In the recent literature $\sigma$ there is no uniformity of opinion regarding the length of time that conservative treatment should be given while hoping for the fistula to seal off, and before deciding to open the chest, although ${ }_{T}$ all agree that such a trial should be made. Some ${ }^{-}$ advocate repeated aspirations for one week, $\overrightarrow{\mathbb{D}}$ followed by tube drainage for a further week before exploration (Seaman, 1954 ; Greenberger $\frac{\varrho}{\sigma}$ and Hurwitz, 1957), while others would persist for as long as three to four weeks (Maloney and 8 Spencer, 1956; Steiger, Weinberg, and Fell, 
1960). Most advocate a fat-free, high-carbohydrate, high-protein diet, and all are agreed that the reinfusion of aspirated chyle is dangerous and should not be done (Whitcomb and Scoville, 1942), although this has been achieved safely in the past on a huge scale (Little et al., 1942).

\section{Plan for the Management of Traumatic ChylothoraX}

No rigid plan will satisfy the demands of all the circumstances in which chylothorax can occur.

There is a choice of three courses that can be followed, which may be effective singly or in combination.

First, in the light of the published experience of others, there is much to be said for the operative control of a chylous leak as soon as possible after establishing the diagnosis, if morbidity and mortality are to be kept to a minimum. Early operation is indicated if the chylothorax is loculated and contains fibrin clot, and in all instances where the lung is "trapped" and requires decortication, possibly as the result of delayed diagnosis. Exploration without delay should also be made if there is uncertainty about the exact pathology, when waiting might postpone appropriate treatment for a previously unsuspected underlying neoplasm.

Secondly, if a period of conservative treatment is decided upon, the physiological facts already presented show that the only efficient way to reduce thoracic duct flow to a minimum, and thereby to reduce flow through the fistula to a minimum, is to stop all nourishment by mouth and to keep the gastrointestinal tract as empty as possible by gastric suction. It follows that the patient must be fed intravenously, and in addition to the calculated daily fluid and electrolyte requirements any observed loss of chyle should be made good with plasma. Intravenous fluids do not of themselves cause an increase in thoracic duct lymph flow. If given in sufficient quantity or in sufficient concentration to cause an increase in blood volume, then a passive increase in lymph flow will follow. The work of Beck (1924), which was concerned with lymph pressure and not lymph flow, is sometimes misquoted in this respect.

The method of chest drainage during this period should be by intercostal catheter, or by drainage tubes put in at operation, with gentle suction, from the outset. This is more efficient than repeated aspiration, and ensures full expansion of the lung all the time instead of intermittently. The clotting properties of chyle are variable, but, to avoid blockage of the intercostal catheter, silicone may be applied to the inside of it (Harkins, 1960). Morphia has a variable effect on thoracic duct flow, but should be given in repeated small doses, and probanthine may be given to suppress intestinal movement and secretion.

A period of seven days is put forward as the maximum time to follow this conservative plan, unless there is evidence that the volume of drainage is becoming progressively less. If during this period the fistula appears to have closed spontaneously, a high-fat test meal may be given before removing the chest tube to make sure that closure is complete. During the conservative trial period, daily plasma protein and serum electrolyte estimations, white blood cell counts, and chest radiographs should be made. If lymph continues to drain steadily, then thoracotomy should be undertaken without delay.

Thirdly, circumstances may strongly contraindicate thoracotomy and demand prolonged conservative treatment. If this is so, for example, in a patient with vertebral or multiple injuries, or immobilized following anterior fusion of the thoracic spine, then failure of the plan already outlined should be followed by the fat-free diet régime, with continued chest drainage. This régime, which has proved effective in practice (Lowman et al., 1951), may be preferable from the beginning in such cases, provided the limitations of the method are realized and that a careful watch is kept on the patient's nutritional state. No mention has been found in the literature of the effect of persistent chyle loss on wound healing.

\section{ChylothoraX IN INFANCY}

Neonatal chylothorax and that occurring postoperatively in small babies presents a special problem (Randolph and Gross, 1957 ; Feinerman, Burke, and Olsen, 1957). Conservative treatment for three weeks is recommended by Randolph and Gross in their comprehensive study of this condition, which contains a wealth of information. The problem of maintaining a small infant with chylothorax in metabolic equilibrium must be very great. The good results of early surgical closure of the fistula may indicate, particularly in places where the most skilled supportive treatment is not available, that operative treatment carries the lesser risk (Steiger et al., 1960).

\section{Chylothorax in Malignant Disease}

Thoracic duct ligation for the control of chylothorax, even in advanced malignant disease, may be the kindest and quickest way of ridding the 
patient of "a most uncomfortable complication" (Klepser and Berry, 1954).

\section{Surgical Technique}

In unilateral chylothorax the chest should be opened on the side of the effusion. The many advantages of operating on the involved side outweigh the arguments in favour of a routine rightsided approach (Baldridge and Lewis, 1948), of which the sole merit is ease of access to the main duct just above the diaphragm. When the effusion is bilateral, it is sensible to explore the right side first, ligating the duct, although it may prove necessary to explore the left side later.

\section{Finding THE Duct AND THE LEAK}

The simplest way to make it easy to find the duct and the leakage point is to give the patient butter or cream to eat three to four hours before operation. The objection to this method is that the stomach may not be empty in time before induction of anaesthesia, although any excess could be removed by the Ryle's tube. A lipophilic dye may be added to the fat if so desired, but the whiteness of chyle is usually sufficiently striking without the addition of colour.

The subcutaneous injection of normal saline causes a temporary increase in thoracic duct flow, and has proved useful in a case of post-operative chylothorax (Steiger et al., 1960).

A $1 \%$ aqueous solution of Evans blue injected into the lower leg results in staining of the thoracic duct within five minutes and lasting for 12 minutes (Merrill, 1955). The recommended dosage is 0.7$0.8 \mathrm{mg} . / \mathrm{kg}$., and a total dose of $25 \mathrm{mg}$. should not be exceeded.

A vital stain, direct sky blue, when injected into the oesophageal wall immediately above the diaphragm, is followed by staining of the thoracic duct (Cohn, Leon, and Strug, 1958): $5 \mathrm{ml}$. of the dye is mixed with $0.2 \mathrm{ml}$. hyalase, $3 \mathrm{ml}$. of the mixture being used.

The disadvantage of dye methods is that the surrounding tissues are also stained when there is free escape of chyle: it is possible that their chief use is a prophylactic one, if they are used to show up the duct at operations in its vicinity.

Operative thoracic ductography (Stranahan et al., 1956) helps to give precise information of the anatomy of the duct, but many chylothoraces have been cured without this extra information.

\section{The Control of THE Fistula}

There are three main techniques that can be used to control the leak of chyle. These are the direct control of the fistula, suture of the leaking mediastinal pleura, and supradiaphragmatic ligation of the thoracic duct.

The best method is to find the actual point of leakage and to ligate the duct on either side of the defect. This may not be possible, particularly in infants and small children, if the mediastinal tissues are extensively soaked in chyle or when there are multiple leaks. Under these circumstances it has been proved sufficient to suture the mediastinal pleura at the point or points where the chyle is leaking (Seaman, 1954; Randolph and Gross, 1957), or to ligate the main duct below.

Either of the first two techniques may be combined with ligation of the thoracic duct low in the chest, which alone has proved entirely effective in many instances in which no attempt has been made to gain direct control of the fistula (Klepser and Berry, 1954).

Re-implantation of the divided duct into a vein (Deanesly, 1903 ; Hodge and Bridges, 1948) and repair of the lacerated duct (Cushing, 1898) are complicated and unnecessary.

\section{Thoracic Duct Fistula as a Therapeutic MEASURE}

The deliberate making of a thoracic duct fistula in the neck, or lymphaticostomy, in the management of peritonitis is of historical interest only (Costain, 1922; Cooke, 1924). More recently, thoracic duct drainage has been tried in the treatment of uraemia (Cronemiller, Byron, and Bierman, 1959). The urea nitrogen content of thoracic duct lymph equals that of the blood, and the creation of a thoracic duct fistula in a uraemic person creates an extrarenal route for removal of nitrogenous waste substances. The results in Cronemiller's small series show that a significant fall in blood urea nitrogen can be achieved which is not explained by any coincidental improvement in renal function.

\section{SUMMARY}

The surgical anatomy, physiology, and pathology of the thoracic duct have been described.

Based on information from many sources regarding the normal and abnormal working of the thoracic duct, a plan for the management of chylothorax is presented. The crucial problem of the conduct of the conservative management of a thoracic duct fistula is emphasized.

The surgical techniques which can be used to cure the leak of chyle into the chest have been given. 
The possible value of thoracic duct drainage as an adjunct to the treatment of uraemia has been mentioned.

\section{REFERENCES}

Acevedo, D. (1943). Amer. J. Physiol., 139, 600.

Alexander, H. L., Shirley, K., and Allen, D. (1936). J. clin. Invest., $15,163$.

Auld, W. H. R., and Needham, C. D. (1951). Lancet, 1, 991.

Baffes, T. G., and Potts, W. J. (1954). Ann. Surg., 139, 501.

Baldridge, R. R., and Lewis, R. V. (1948). Ibid., 128, 1056.

Beck, C. S. (1924). Johns Hopk. Hosp. Bull., 35, 206.

Birt, A. B., and Connolly, N. K. (1952). Brit. J. Surg., 39, 564.

Blalock, A., Robinson, C. S., Cunningham, R. S., and Gray, M. E. (1937). Arch. Surg. (Chicago), 34, 1049.

Bland-Sutton, J. (1917). Tumours Innocent and Malignant, 6th ed., pp. 259, 658. Cassell, London.

Calenda, D. G., and Harris, J. H. (1952). J. Amer. med. Ass., 149, 1016.

Cohn, I., Leon, W., and Strug, L. H. (1958). Ann. Surg., 148, 867.

Cooke, A. (1924). Brit. med. J., 1, 1048.

Costain, W. A. (1922). Canad. med. Ass. J., n.s. $12,789$.

CoTui, Barcham, I. S., and Shafiroff, B. G. P. (1944). Surg. Gynec. Obstet., $79,37$.

Crafoord, C. (1941). Acta chir. scand., 85, 99.

Crandall, L. A., and Barker, S. B. (1943). Gastroenterology, 1, 1040.

Cronemiller, P. D., Byron, R. L., and Bierman, H. R. (1959). Surg. Gynec. Obstet., 109, 355.

Cushing, H. W. (1898). Ann. Surg., 27, 719.

Davis, H. K. (1915). Amer. J. Anat., 17, 211.

Deanesly, E. (1903). Lancet, 2, 1783.

Dillard, R. A., and Perkins, R. B. (1958). J. thorac. Surg., 35, 91.

Dumont, A. E., and Mulholland, J. H. (1960). Gastroenterology, 38, 954.

Ehrenhaft, J. L., and Meyers, R. (1948). Ann. Surg., 128, 38.

Emerson, G. L. (1950). New Engl. J. Med., 242, 575.

Feinerman, B., Burke, E. C., and Olsen, A. M. (1957). Proc. Mayo Clin., 32, 314.

Fernandes, J., van de Kamer, J. H., and Weijers, H. A. (1955). J. clin. Invest., 34, 1026.

Frazer, A. C. (1943). J. Physiol. (Lond.), 102, 306.

Garamella, J. J. (1958). A.M.A. Arch. Surg., i6, 46.

Gaspar, M. R., and Secrest, P. G. (1957). Ibid., 75, 193.

Goorwitch, J. (1955). J. thorac. Surg., $29,467$.

Gray's Anatomy (1958), 32nd ed., p. 882. Longmans, Green, London.

Greenberger, G., and Hurwitz, A. (1957). J. thorac. Surg., 34, 399.

Harkins, G. A. (1960). J. thorac. cardiovasc. Surg., 40, 549.

Hodge, G. B., and Bridges, H. (1948). Surgery, 24, 805.

Judd, E. S., and Nix, J. T. (1949). Surg. Clin. N. Amer., $29,1035$.
Kausel, H. W., Reeve, T. S., Stein, A. A., Alley, R. D., and Stranahan, A. (1957). J. thorac. Surg., 34, 631.

Kinmonth, J. B., and Sharpey-Schafer, E. P. (1960). Personal communication.

- and Taylor, G. W. (1956). J. Physiol. (Lond.), 133, 3P.

Klepser, R. G., and Berry, J. F. (1954). Dis. Chest, 25, 409.

Lampson, R. S. (1948). J. thorac. Surg., 17, 778.

Lee, F. C. (1922). Johns Hopk. Hosp. Bull., 33, 21.

Likoff, W., Berkowitz, D., Woldow, A., Jacobs, A. G., and Sklaroff, D. M. (1958). Circulation, 18, 1118 .

Little, J. M., Harrison, C., and Blalock, A. (1942). Surgery, 11, 392.

Loe, R. H. (1946). Arch. Surg. (Chicago), 53, 448.

Lowman, R. M., Hoogerhyde, J., Waters, L. L., and Grant, C. (1951). Amer. J. Roentgenol., 65, 529.

McGregor, A. L. (1953). Brit. J. Surg., 40, 569.

Maloney, J. V., and Spencer, F. C. (1956). Surgery, 40, 121.

Maurer, E. R. (1956). J. Amer. med. Ass., 161, 135.

Meade, R. H.(1952). A.M.A. Arch. intern. Med., 90, 30.

- Head, J. R., and Moen, C. W. (1950). J. thorac. Surg., 19, 709.

Merrill, K. (1955). Ibid., 29, 555.

Randolph, J. G., and Gross, R. E. (1957). A.M.A. Arch. Surg. (Chicago), ;4, 405.

Robinson, C. S., Cunningham, R. S., Blalock, A., Gray, M. E., and Rogers, B. C. (1937). Arch. Path. (Chicago), 24, 303.

Schnug, E., and Ransohoff, J. (1943). Surgery, 14, 278.

Seaman, J. B. (1954). J. thorac. Surg., $27,529$.

Shackelford, R. T., and Fisher, A. M. (1938). Sth. med. J. (Bgham, Ala.), 31, 766.

Shafiroff, B. G. P., and Kan, Q. Y. (1959). Surgery, 45, 814.

Shumacker, H. B., and Moore, T. C. (1951). Surg. Gyner. Obstet., 93, 46.'

Steiger, Z., Weinberg, M., and Fell, E. H. (1960). Amer. J. Surg., $100,8$.

Stranahan, A., Alley, R. D., Kausel, H. W., and Reeve, T. S. (1956). J. thorac. Surg., 31, 183.

Touroff, A. S. W., and Seley, G. P. (1953). Ibid., 26, 318.

Thorne, P. S. (1958). Tubercle (Lond.), 39, 29.

Van Pernis, P. A. (1949). Surgery, 26, 806.

Watne, A. L., Hatiboglu, I., and Moore, G. E. (1960). Surg. Gynec. Obstet., 110, 339.

Whitcomb, B. B., and Scoville, W. B. (1942). Arch. Surg. (Chicago), 45, 747.

Willis, R. A. (1952). The Spread of Tumours in the Human Body. Butterworth, London.

Wright, S. (1945). Applied Physiology, 8th ed., p. 548. Oxford University Press, London.

Yater, W. M. (1935). Ann. intern. Med., 9, 600.

Yoffey, J. M., and Courtice, F. C. (1956). Lymphatics, Lymph and Lymphoid Tissue, 2nd ed. Arnold, London. 